\title{
The Challenge of Closed-Loop Supply Chains
}

\author{
V. Daniel R. Guide Jr. • Terry P. Harrison \\ Department of Supply Chain and Information Systems, Smeal College of Business Administration, \\ Pennsylvania State University, University Park, Pennsylvania 16802 \\ Luk N. Van Wassenhove \\ Technology Management Area, INSEAD, Boulevard de Constance, 77305 Fontainebleau Cedex, France \\ dguide@psu.edu・tharrison@psu.edu・luk.van-wassenhove@insead.edu
}

\begin{abstract}
Closed-loop supply chains differ significantly from forward supply chains in many aspects. These differences are not well understood in many contexts, and the situation is complicated by many types of product returns. Progress is slow since closed-loop supply chains are rarely considered as value-creating systems, and much of the focus is on the operational aspects, rather than the larger strategic issues. Interest is growing in the US because of the potential profitability and in the European Union because of legislation. New business models need to be developed by joint cooperation between industry and academia that take a life-cycle approach to products.
\end{abstract}

(Facilities, equipment planning: capacity expansion. Manufacturing: performance, productivity.)

$\mathrm{I}^{\mathrm{n}}$ a forward supply chain, the customer is typically the end of the process. However, a closedloop supply chain includes the returns processes and the manufacturer has the intent of capturing additional value and further integrating all supplychain activities. Therefore, closed-loop supply chains include traditional forward supply-chain activities and the additional activities of the reverse supply chain. These additional activities include

- product acquisition to obtain the products from the end-users,

- reverse logistics to move the products from the points of use to a point(s) of disposition,

- testing, sorting, and disposition to determine the product's condition and the most economically attractive reuse option,

- refurbishing to enable the most economically attractive of the options: direct reuse, repair, remanufacture, recycle, or disposal, and

- remarketing to create and exploit markets for refurbished goods and distribute them.
A reverse supply chain requires careful design, planning, and control. Until researchers define the proper context for reverse supply chains, they will be different in nature from forward systems. Although we have established common activities for reverse supply chains, we do not completely understand these activities in different contexts because they vary in complexity and managerial importance from scenario to scenario. The situation is further complicated because users may return products during the product life cycle (commercial returns: a result of liberal reseller policies that permit customers to return products for any reason during a 30-, 60-, or 90-day period after purchase, warranties, repairs), at end of use, and at end of life. Each type of return requires a reverse supply chain appropriate to the characteristics of the returned products to optimize value recovery.

Corporate managers view forward supply chains as important, pay attention to them, and create supporting services to make these processes fluid and effective from end to end. Forward supply chains 
incorporate many interdisciplinary elements, including legal issues, governmental policies, environmental concerns, and collaboration (contracts) with partners. Active, established, and rigorous academic research programs are dedicated to understanding and improving forward supply chains.

Today, those in industry and academia rarely consider the reverse supply chain as a business process. Instead, they look at it as a series of fairly independent activities, that is, they use a silo approach to reverse supply chains, considering each activity in isolation without considering the integrated nature of reverse supply chains. In addition, people in both industry and academia focus on the operational or tactical, as opposed to the strategic. Both groups assume that the larger strategic question of profitability has already been resolved, which is incorrect. In our experience, many firms look at remanufacturing as a technical operational problem: how to turn an illfunctioning returned product into a functioning product that satisfies all the quality requirements of a new product.

Companies often passively accept returns from the market or the channel. They do not actively manage the process of acquiring returns; hence, returns are uncertain in quality, quantity, and timing, and the companies do not align the corresponding remanufacturing costs and selling opportunities. Similarly, sales and marketing departments are not concerned with remanufacturing. At best, they are neutral; more often they fear remanufactured sales will cannibalize new sales and damage brand image. Also, salespersons typically get lower commissions for selling remanufactured products than they would for selling new products. Sales channels for remanufactured products are ill developed, and sales quantities and timing are uncertain. Finally, companies rarely encourage design engineers to design products to facilitate disassembly or easy remanufacturing.

Researchers and practitioners working on reverse supply chains can learn from practices used in forward supply chains, but first they need to adopt a business approach to the entire process (Guide and Van Wassenhove 2003). By concentrating on the technical aspects of remanufacturing, passively accepting returns, and spending little effort in developing sales channels for the remanufactured products, they will not make reverse supply chains effective, let alone profitable.

In taking a silo approach to reverse supply chains, managers ignore the importance of speed. They commonly view fast response time as essential for forward supply chains, especially in fast clockspeed industries in which products' value erodes rapidly. Given consumers' increasing tendency to return products to resellers (commercial returns), taking a passive approach to the reverse process can slow the returns' velocity so much that most of the value in the remanufactured products is lost by the time they hit the market again.

A company with the right business model must implement it carefully and integrate the reverse-supplychain processes. Reverse supply chains and their contexts are not yet stable and well defined; all the stages in the chain (acquisition; reverse logistics; sorting, testing, and disposition; remanufacturing; and remarketing) are potential showstoppers. The activities are interrelated, mutually reinforcing, and often dependent on business functions outside the supply chain, such as marketing and product design. Given that reverse supply chains are not near a firm's core business, aligning their elements, obtaining the right resources, and getting top managers' attention is difficult. Forward supply chains have many of the same requirements, but the issues and the context for reverse supply chains are still little understood and command little attention. Dekker et al. (2003) describe quantitative models of reverse logistics.

\section{Previous Research and Current Practice}

Reverse and closed-loop supply chains, including remanufacturing, are not new. Some industries have been remanufacturing since the 1920s (for example, automotive parts have long been remanufactured by third parties). Manufacturers designed large, expensive assets, such as steam locomotives, for extended product lives as long ago as the 1800s. Aircraft and ships are still designed to be maintained for very long periods. The military has routinely remanufactured assets for decades. Research on remanufacturing has 
increased since the early 1980s (Lund 1983), with most of the published research appearing since 1990 and focused on operational or engineering issues.

Considerable research has concerned "green supply chains" or "environmentally responsible manufacturing." However, no rational company will invest in environmental measures to save the earth. That's not what companies are for, and legislation is not going to change that, except perhaps to make things worse if we are not careful. Legislation may impose constraints on companies that increase costs and environmental impact. Companies will then require their customers to absorb these costs. In short, companies see preserving the environment as a burden, a cost to be minimized, not an opportunity. Companies need a viable business model that marries good business sense with environmental sustainability and allows companies to realize value out of returned products.

In some cases, sustainable solutions will never be profitable, no matter how intelligent or innovative the business model. In those cases, legislation may be the only solution. But our general view is that legislation can and should be a gentle push to businesses to pay attention and overcome the hurdle. It should be flexible, giving businesses the chance to organize systems and solutions themselves, and it should be temporary, to be suspended when businesses solve the problems of environmental degradation.

In the United States, companies have become increasingly interested in reverse supply chains for economic reasons, and in the European Union (EU), companies have become interested because of legislation. Until recently much of the remanufacturing was concentrated in limited-volume operations for goods of very high value. However, companies now remanufacture large volumes of low-value items, for example, mobile telephones and ink-jet printers. Companies in the US must also deal with the returns of commercial products during their life cycles. Top managers are starting to pay attention to such returns in a few companies, because US companies are losing so much value there ( $\$ 100$ billion annually).

\section{Future Challenges}

Increased global competition, shortened life cycles, expanded environmental legislation, and ever more lenient commercial take-back policies at resellers for customers will increase product returns. Decreasing profit margins in global markets with overcapacity, together with increased returns that will be expensive to handle if products and business processes have not been designed to accommodate them, will lead to losses. Companies will realize that they need a lifecycle approach to products, that is, an approach that integrates all product returns (commercial returns, warranty returns, repairs, end-of-use returns, and end-of-life returns) into the business model for the product. Companies must design the forward supply chain and the reverse supply chain to take advantage of all types of product returns and to include final environmentally friendly disposal. This life-cycle approach goes beyond current ideas for the forward supply chain. The pressure on companies to find better ways to handle returns should lead them to explore new territory in managing supply chains.

Going one step further still, in their concern for product returns of different types during the life cycle, companies may develop business models in which they replace product ownership with creative service offerings. They may turn to providing services rather than products. Again, researchers into traditional supply chains would have to venture into unexplored or currently insufficiently explored territories. These changes may have the side benefit of aligning the business concern of creating value with the industrial-ecology concern for sustainability and help to resolve the perceived or real conflict between profit and the environment by showing that business that is sustainable from an ecological perspective can be sustainable from a profit perspective as well.

The world is changing very rapidly, and companies, in cooperation with academics, must quickly develop supply chains that can handle coordinated forward and reverse flows of materials. First and perhaps foremost, they must develop methods of showing managers the benefits to be obtained by developing reverse supply chains. If managers cannot quantify the potential financial (and nonfinancial) benefits, they are unlikely to consider return flows as anything other than a nuisance, for which they must minimize losses. Second, they must adopt new business models that show top managers how to release 
the enormous value that is currently unrecognized and unappreciated. Finally, they must adopt new operational models to help them to manage the dayto-day tactical elements so that they can realize their business objectives.

Today, the interesting problems for business are not tactical or operational in nature. They tend to be strategic and somewhat unstructured. Researchers can invest a lot of time trying to understand the issues in practice by digging into the details of how companies do things today in reverse supply chains. A researcher who understands several companies can generalize some issues in a sector, structure the problem, make abstractions, and formulate a model that will lead to nice, clean (publishable) results. Many researchers aiming to publish in top journals to obtain tenure or promotion do not have the patience or the time to do all of this. It is much easier to work in a well-developed and conventional problem area and to derive an extension to an existing body of results.

The researchers focusing on conventional supply chains, like researchers in any field, may be conservative and reluctant to change. They may find it uncomfortable to acknowledge new issues that challenge existing notions and well-developed jargon. It is easier to assume "there is nothing new under the sun. It is all an extension of forward supply chains." Such a reaction is normal, human, and intrinsically sound. Scientists need to be careful (conservative) but not blind to new concepts that challenge or enrich the discipline.

Closed-loop supply chains open up a new and interesting set of issues to be addressed by industry. They also offer opportunities for meaningful academic research that takes into consideration the interdisciplinary nature of the problems and the need to develop frameworks and models based on an integrated-business-process perspective.

\section{References}

Dekker, R., M. Fleischmann, K. Inderfurth, L. N. Van Wassenhove, eds. 2003. Reverse Logistics-A Quantitative Approach. SpringerVerlag, Berlin, Germany.

Guide, V. D. R., Jr., L. N. Van Wassenhove, eds. 2003. Business Aspects of Closed-Loop Supply Chains. Carnegie Mellon University Press, Pittsburgh, PA.

Lund, R. 1983. Remanufacturing: United States Experience and Implications for Developing Nations. World Bank, Washington, DC. 